A Defence of Free Learning

By Lord Beveridge. Pp. xiv +146 . (London: Oxford University Press, 1959.) 18s. net.

T this book Lord Beveridge has drawn in the main on the documents collected for their work by the Academic Assistance Council and the Society for the Protection of Science and Learning to give a sober but moving narrative of twenty-five years work in Britain to help university teachers and scholars driven from their work on political or racial grounds. It is not a philosophical or theoretical argument for academic freedom but a factual account of what has been done in Britain alone, beginning with the expulsions from Germany initiated by Hitler in 1933 and continuing down to the problems presented by the intolerance persisting after the Second World War, including the Hungarian persecution of 1956-57. It is a story little known outside the universities and is told without embellishment, save, perhaps, where in his concluding chapter "The Folly of Tyrants", Lord Beveridge, summarizing, points to the rich harvest which Britain has reaped by her reception of these refugees. There are indeed some dark places in the story and Lord Beveridge does not attempt to conceal them. On the other hand, he does not overstress them and points out fairly enough that, even in the darkest hour of 1940, there were always those in Britain ready to protest vigorously against administrative error or tardiness and to insist on the revocation of stupid decisions. Five debates in the House of Commons in less than eight months of desperate war testify to a sense of justice and a vigilance of which Britain has a right to be proud. The most moving chapter is, perhaps, that entitled "Wandering Scholars", in which Lord Beveridge sets forth some of the typical experiences of these scholars collected from their replies to an inquiry sent out in June 1958. No eloquence could make the human issues plainer, nor is more needed by way of argument to demonstrate that here is a continuing problem calling for forethought and imagination, as well ass practical help if its difficulties are to be resolved and some of the existing gaps, notably in relation to professional work, are to be closed.

In writing this book, Lord Beveridge has added to the debt which Britain as well as wandering scholars owe him and his colleagues, first on the Academic Assistance Council and then in the Society for the Protection of Science and Learning.

\section{R. Brightman}

Systematic Mineralogy of Uranium and Thorium (Bulletin 1064, U.S. Geological Survey.) By Clifford Frondel. Pp. viii +400 . (Washington: U.S. Govt. Printing Office, 1958.) 1.50 dollars.

$F^{O R}$ the past ten years an intensive investigation into the mineralogy of uranium and thorium, undertaken in connexion with economic studies of radioactive ore supplies, has been in progress in the laboratories of the U.S. Geological Survey, the U.S. National Museum, and the Mineralogical Department of Harvard University. The vast amount of new information forthcoming from these researches has now been assembled by Prof. Frondel of Harvard, in a monograph which is quite the most outstanding work among the half-dozen or more major text-books on radioactive mineralogy that have appeared in the U.S.S.R., North America and France during the past two years. Each of close on a hundred mineral species is very fully deseribed according to its synonymy, composition, crystallography and crystal habit, physical and optical properties (with X-ray powder diffraction interplanar spacings), synthesis, criteria for identification, mode of formation, and natural occurrence. Comprehensive determinative tables are given in an appendix and there is a bibliography of 800 items. Although the work has been three years in the press and thus gives no account of the most recent discoveries, no earlier book in this field has achieved anything like the same coverage and certainly none can parallel this inexpensive Bulletin in accuracy of data and freedom from misprints. Most of the opaque multiple-oxide minerals of uranium, other than species of economic importance such as brannerite, davidite, and the pyrochlore-microlite series, have still to be studied in detail; for the rest, the many geologists and mineralogists now concerned with uranium ores will unhesitatingly accept this monograph as their foremost authority. $\quad$ C. F. DAvidson

\section{Numerical Analysis and Partial Differential Equa- tions}

By George E. Forsythe and Paul C. Rosenbloom. (Surveys in Applied Mathematics, Vol. 5.) Pp. x+ 204. (New York: John Wiley and Sons, Inc.; London: Chapman and Hall, Ltd., 1958.) 60s. net.

THIS survey contains two unrelated essays. In the shorter of the two, Forsythe summarizes recent work in numerical analysis, with special references to developments in the U.S.S.R. There is an account of the chief Russian automatic computers, details of which have been available only in the past two or three years. Forsythe also stresses the skill with which Russian workers have brought to the service of numerical analysis some of the most up-to. date tools of pure mathematics, such as constructive function theory and functional analysis. The bibliography is helpfully selective rather than blindly comprehensive, and the author's eomments on the various items are crisp and efficient.

Rosenbloom's essay does not attempt to describe all recent contributions to the study of partial differential equations, but it gives a valuable indica. tion of the way in which the theory of function spaces and the transform calculus have yielded fresh results about elliptic and parabotic equations. The young research worker should find this a helpful guide to some of the main lines of advance ; the bibliography, of some 700 items, may well frighten the novice, and some further annotation would have been an advantage.

T. A. A. BroadbeNt

Clinical Biochemical Method

By Dr. A. L. Tárnoky. Pp. $x+239$. (London : Hilger and Watts, Ltd., 1958.) 50s. net.

MOST large clinical biochemistry laboratories 1 have their own particular methods for routine examinations, or more likely use modified classical ones in the light of their experience. Dr. A. L. Tárnoky's book describes the methods used routinely in his laboratory at the Royal Berkshire Hospital. It is a straightforward bench manual giving most of the usual tests arranged in alphabetical order. Each test is described under the headings of principle, specimen required, method, result, normal value, reagents required and remarks. There is a small but valuable appendix which gives procedures for checking analyses in a laboratory, lists of books and references and a list of manufacturers. There are 